\title{
Author Correction to: Extreme Learning Machine Framework for Risk Stratification of Fatty Liver Disease Using Ultrasound Tissue Characterization
}

\author{
Venkatanareshbabu Kuppili ${ }^{1,2}$ • Mainak Biswas ${ }^{1}$ - Aswini Sreekumar ${ }^{1}$. \\ Harman S. Suri ${ }^{2,3,4} \cdot$ Luca Saba $^{5}$ - Damodar Reddy Edla ${ }^{1} \cdot$ Rui Tato Marinho ${ }^{6}$. \\ J. Miguel Sanches ${ }^{7} \cdot$ Jasjit S. Suri $^{2}$
}

Published online: 7 December 2017

(C) Springer Science+Business Media, LLC, part of Springer Nature 2017

Author Correction to: J Med Syst (2017) 41: 152

https://doi.org/10.1007/s10916-017-0797-1

The original version of this article unfortunately contained a mistake. The family name of Rui Tato Marinho was incorrectly spelled as Marinhoe.

The online version of the original article can be found at https://oi.org/ 10.1007/s10916-017-0797-1

\footnotetext{
Jasjit S. Suri

jsuri@comcast.net

1 Department of Computer Science and Engineering, National Institute of Technology Goa, Farmagudi, India

2 Global Biomedical Technologies, Inc., Roseville, CA, USA

3 Brown University, Providence, RI, USA

4 Mira Loma, Sacramento, CA, USA

5 Department of Radiology, Azienda Ospedaliero Universitaria (A.O.U.), Cagliari, Italy

6 Liver Unit, Department of Gastroenterology and Hepatology, Hospital de Santa Maria, Medical School of Lisbon, 1629-049 Lisbon, Portugal

7 Bioengineering Department, Instituto Superior Tecnico (IST), University of Lisbon, Lisbon, Portugal
} 